\title{
Network Performance and Competitive Impact of the Single Hub - A Case Study on Turkish Airlines and Emirates
}

\author{
Michail Logothetis and Chikage Miyoshi \\ Centre for Air Transport Management \\ School of Aerospace, Transport and Manufacturing \\ Martell House, College Road, Cranfield \\ Bedford, England MK430TR \\ Email: c.miyoshi@cranfield.ac.uk \\ Telephone: $+44(0) 1234754976$
}

\begin{abstract}
This paper introduces a new model for evaluating connectivity at hub airports. The Hub Connectivity Performance Analyser (HCPA), developed in this context, assesses both schedule- and comfort-related attributes of indirect flights and consolidates the results into two indexes: the Hub Connectivity Performance Index (HCPI) and the Hub Efficiency Index $(\varphi)$. The proposed methodology is used to derive conclusions about the hub performance and efficiency of two modern influential super-connectors: Turkish Airlines and Emirates. Connectivity at Istanbul Atatürk and Dubai International airports is therefore evaluated for the said carriers and their alliance code-sharing partners. Historical growth and key O\&D flows targeted by each carrier are identified and benchmarked to establish the competitive impact of their hubs. Findings indicate that Emirates operates an ultra-efficient hub, which has superior performance to that of Turkish Airlines; however, in a marketbreakdown basis, the dominance is split between the two carriers. Given that both Istanbul Atatürk and Dubai International operate near capacity, the study concludes that the way forward for both carriers is either to opt for up-gauging their fleet or targeting higher hub efficiency.
\end{abstract}

Published by Elsevier. This is the Author Accepted Manuscript issued with: Creative Commons Attribution Non-Commercial No Derivatives License (CC:BY:NC:ND 4.0) The final published version (version of record) is available online at DOI:10.1016/j.jairtraman.2016.10.003 Please refer to any applicable publisher terms of use. 
Keywords: Airline network, hub connectivity, Gulf carriers, Turkish Airlines, Emirates

\subsection{Introduction}

This paper aims to analyse the network strategy of two emerging airlines, Turkish Airlines (TK) and Emirates (EK), in terms of network connectivity at each hub airport.

The aviation industry has witnessed many changes in recent years. The emergence of low-cost airlines corroded the local point-to-point operations of traditional flag airlines and the rise of the 'big three' Gulf carriers, Emirates, Qatar Airways and Etihad, attacked their network and transfer traffic on a global scale. In addition, the transformation of Turkish Airlines into another strong inter-continental connector, building upon Istanbul's excellent geographic location, concluded this significant shift of power away from the now suffering legacy carriers. The secret of success, if any, for these new 'global connectors' lies in the heart of their network model: their large hubs. Thus, an analysis focusing on the factors that influence hub efficiency and the evaluation of hub connectivity for such carriers is deemed worthwhile.

The approach followed herein utilises a case study, centred on two of today's most influential mega-hub airlines, Turkish Airlines and Emirates. Turkish has grown rapidly during the last decade, following Turkey's resurgence. Soon after it ceased being a traditional state-run carrier, Turkish adopted the 'super-connector' operating model, entering into direct competition with the strong Gulf carriers. Similarly, the growth of Emirates has been notably fast-paced since its establishment in 1985, becoming the world's largest airline as measured by international passengerkilometres flown; therefore, Emirates and its mega-hub in Dubai constitute a very interesting case for further study.

An analytical tool, the Hub Connectivity Performance Analyser (HCPA), developed in this context, performs the evaluation of hub connectivity. The analyser scrutinises the published schedules of the chosen airlines and evaluates the quality of all viable connections through their hubs. A connectivity model to assess both schedule- and comfort-related attributes of one-stop services is presented, building upon our previous study (Li et al., 2012). Finally, the paper aims to summarise the results; the Hub Connectivity Performance Index (HCPI) and the Hub Efficiency Index $(\varphi)$ are 
proposed, facilitating the positioning of the two carriers (Turkish Airlines and Emirates) on the competition map.

All published schedules were sourced from the Official Airline Guide (OAG) for the first week of July of each studied year in 2007, 2008, 2014 and 2016. Seasonality of available airline capacity (ASKs) during an annual cycle shows that airlines tend to deploy more capacity in their summer schedules (March to October). As a result, choosing to analyse data for the first week of July will add significance to the findings, since this is expected to be a period of increased activity. What is more, Turkish joined Star Alliance in April 2008, forming numerous codeshare agreements with its new alliance partners. Therefore, selecting 2007 as the base year, when Turkish had not yet joined Star, will reveal the true gain contributed by its partners when compared to a most recent snapshot. Emirates became the first carrier to serve six continents non-stop from a single hub in October 2007 when it launched services to South America. Thus, it is interesting to examine how its network connectivity developed from the following year (2008) onwards. Base year findings are then benchmarked with a 2014 snapshot; as an update, figures produced based on 2016 schedule data are also provided for the purpose of reinforcing the conclusions.

The paper is structured as follows: previous research in the field of connectivity and various approaches for measuring hub connectivity are presented in section 2 . In section 3 , the model proposed in this paper is introduced and its specifics are explained. Then, as a case study, connectivity analysis results for the Istanbul and Dubai hubs are presented and benchmarked, while key O\&D flows for each carrier are also identified in section 4. Finally, key findings are summarised and conclusions are drawn.

\subsection{Hub airport connectivity}

A number of different models have already been proposed in previous studies for the assessment of hub connectivity. Hub connectivity refers to the quantity and quality of indirect flights available to passengers via an airline hub (Bootsma, 1997). Consequently, in a hub connectivity analysis, the researcher has to identify the parameters that affect both quantity and quality of connections. Doganis and Dennis (1989) with their 'Hub Potential' and 'Connectivity' models provided the foundation while Veldhuis (1997) and the 'Netscan' model contributed largely to this field. A 
more recent approach involves the development of optimised connection builders as integrated modules that support airline scheduling based on passenger estimations (Grosche, 2009).

The hub connectivity analysis requires the calculation of the total number of connections ('hits') that can be attained between banks of arriving and departing flights in a hub. Key parameters, essential for the calculation of hub connectivity are Minimum Connecting Time (MCT), Maximum Connecting Time (MACT) and Maximum Geographical Detour (MGD). MCT is the shortest time required to transfer passengers and baggage from the arriving to the departing flight (Seredyński et al., 2014) and depends on both airport-specific parameters and connection type. Airports usually compile and publish monthly updates on the applicable MCTs for all types of connections; however such rules can be very complex for major airports, including hundreds of exceptions. This is why most studies tend to follow a fairly generic approach in selecting MCTs, rather than fully implementing airport rules. MACT on the other hand cannot be objectively quantified, being a measure of the maximum time passengers would tolerate waiting at the hub during a stop-over. Despite the fact that MACT is subjective for each passenger, there are certain factors that influence it. For example, as Veldhuis suggests (Veldhuis, 1997), amenities offered at the hub airport or lower fares may compensate for longer transfer times. In addition, passenger perception of time varies, with transfer-time being perceived longer than time spent on the air (Lijesen, 2004).

One group of researchers adopt fixed values for MCTs and MACTs (see Doganis and Dennis, 1989; Bootsma, 1997; Veldhuis, 1997; Burghouwt and de Wit, 2005; Danesi, 2006; Budde et al., 2008), while others simply qualify connections without applying such limits (see Bania et al., 1998; Dennis, 1998; Malighetti et al., 2008). Table 1 summarises the different practices that various researchers have followed.

Suau-Sanchez and Burghouwt (2012) have followed the same approach proposed by Veldhuis, but they adopted an explicit and higher MACT of 760 minutes. Another study introduces the 'maximum connection lag' as a key variable that incorporates the effect of both the connection time and the geographical detour (Seredyński et al., 2014); this approach favours connections with shorter detours by allowing longer connection times. Most methodologies utilise routing factors and thus exclude connections involving significant back-tracking (Burghouwt and de Wit, 2005; Danesi, 2006; Malighetti et al., 2008). Veldhuis (1997) developed the 'Netscan' which follows a different course; instead of constraining the routing factor, the model penalises 
connections involving high detours by attaching to them lower quality indexes. Several studies that adopt the shortest/quickest path methodology limit excessive routing factors by definition (see Shaw, 1993; Shaw and Ivy, 1994; Malighetti et al., 2008). Typical values for route factors proposed and used in past literature are listed in Table 1.

After all viable connections have been identified, connection quality can be evaluated as an important element of the level of service provided by any airline. In this process, various factors (including comfort-related ones) are assessed and consolidated into a single connection-specific quality index. This index is introduced to capture the market appeal of that connection, or in other words, how its value proposition compares to that of a potential direct flight between the same O\&D pair. There are three different approaches in evaluating connection quality with the simplest of all being the binary one: the connection is deemed feasible if it meets transfer time and detour thresholds (for example see Dennis, 1994a; 1994b; Budde et al., 2008; Malighetti et al., 2008). In a more detailed level, discrete approaches classify connections according to a qualitative attribute, such as 'poor', 'good' and 'excellent' (see Bootsma, 1997; Danesi, 2006). Finally, the 'Netscan' model (Veldhuis, 1997) and subsequent studies based on it (see Veldhuis and Kroes, 2002; Burghouwt and de Wit, 2005; Burghouwt, 2007; Matsumoto et al., 2008) implement the continuous quality index. This approach attempts to quantify various parameters that affect the market appeal of one-stop operations and is likely to lead to more robust conclusions. Such parameters include but are not limited to the following: transfer time, availability of direct services from competitors, arrival/departure hours, value/frequency of connections, airport facilities and equipment type (Goedeking, 2010; Li et al., 2012). Most researchers incorporate the values of routing, time and competition factors into a single quality index, which is then attached to each feasible connection; for example, van Dalen (van Dalen, 2011) built upon our previous model (Li et al., 2012) by introducing a competition factor. Thus, each indirect connection gains or loses market appeal according to the number of direct seats supplied by competitors: the more direct seats supplied, the less favourable an indirect connection between the same O\&D pair becomes. 


\subsection{Methodology for the Hub Connectivity Performance Analyser (HCPA)}

The Hub Connectivity Performance Analyser (HCPA) is proposed as a tool to evaluate connectivity performance and comprises two separate modules: the quantity module and the quality module, developed based on the methodology presented in our previous study ( $\mathrm{Li}$ et al., 2012). Each of these modules contains various sub-modules that assess different aspects of indirect services. The HCPA receives as input the flight schedules database, and after evaluating connectivity, it exports the results in a new database.

\subsection{Quantity of Connections}

A pair of arriving and departing flights that allow sufficient time for passengers to change planes is defined as a 'viable connection' or 'hit'. The total number of connections within a certain time period is the maximum number of connections that can be exploited by a passenger travelling through the hub, so it can serve as a measure of the hub's connecting potential. In order to estimate this number, HCPA analyses published airline schedules along with the MCT and MACT limits that have been selected.

MCT values were directly sourced from OAG, as reported by the respective airport authorities, adding to the originality of the study. MACTs, however, as mentioned before, are not influenced by any operational constraints and are rather subjective; most researchers tend to adopt arbitrary values that will facilitate the formation of sufficient transfer windows, with all generated connections being filtered at a later stage based on their individual quality attributes. For the purpose of maintaining consistency with our previous study (Li et al., 2012) MACT was selected to be three times the corresponding MCT. MCT/MACT values for Istanbul Atatürk and Dubai International are summarised in Table 2.

The flight schedules database includes all flights arriving and departing from a particular hub; origin and destination, date and time of departure/arrival, flying duration, total distance, seats and aircraft type are all listed in this database. Then, for each day of the week, the algorithm screens all arriving flights and establishes the number of outbound flights that each inbound service can feed into, satisfying both MCT and MACT constraints. The sum of all such connections represents the hub's quantity of connectivity, i.e. Quantity of Viable Connections (QVC) (Equation 1).

$\mathrm{QVC}=\sum_{\text {day }=1}^{7}\left[\sum_{\text {inbound flight }=1}^{n}\right.$ connection $]$, where $n=$ total inbound flights eq. 1 
After the hub's quantity of connectivity has been calculated, the need to weigh achievable connections based on their value and market appeal arises, which is addressed by the quality module.

\subsection{Quality of Connections}

Despite the fact that schedules might allow sufficient time for passengers to deplane and board their onward connection, this does not guarantee that such a connecting opportunity will bear practical value. For example, an Emirates flight from Paris Charles de Gaulle Airport (CDG) arriving into Dubai International Airport (DXB) might allow passengers to transfer to another Emirates flight from DXB to CDG, thus being counted as a viable connection and contributing to the hub's quantity of connectivity. However, such a connection would be of limited value from a passenger's perspective. The same holds true for connections involving high geographical detours (e.g. a flight from London to Paris involving a stop-over in Dubai or Istanbul). Therefore, the quality module is tasked with assigning an individual quality index (QCI) to every connection, qualified by the quantity module.

Researchers commonly use the routing and time factors in order to assess the quality of connections. The Routing Factor (RF) quantifies the underlying detours for each connection and filters out those that involve significant backtracking. The HCPA zeroes out the quality indexes of all connections involving a detour in excess of $50 \%$ and penalises all other connections proportionately to the underlying detour. In addition, connection quality is inversely proportional to the total elapsed time, which itself depends on the ground time or transfer time. The longer the transfer time is, the less appealing a connection becomes. The HCPA model takes this concept one step further by introducing penalty multipliers to be used for artificially increasing transfer time. Passenger perception of time spent on the ground during a transfer changes with the hour of the day during which the transfer occurs. As a result, a measure of 'Perceived Flying Time' is derived, which also feeds in the calculation of the Time Factor (TF).

Most connectivity models derive connection quality based solely on routing factors and time factors. The HCPA methodology, however, attempts to measure the effect of additional influences that shape the value and quality of connections. Seat Factor (SF) emphasizes or de-emphasizes the importance of a connection based on the underlying number of seats on each leg; the more seats involved in a particular connection, the more valuable it is. Another aspect that can be used to weight connections is that of service quality and on-board comfort. It is widely accepted that 
wide-bodied aircraft elevate passenger experience and perceived comfort, due to their spacious cabins and in-flight entertainment systems. What is more, passengers travelling in premium cabins anticipate experiencing a unique product offering (including on-board showers, bars and lounges) which cannot be fulfilled within the limited real-estate of a narrow-body. As a result, HCPA introduces the Service Quality Factor (SQF) which weighs the value of connections based on whether any of the two legs is operated by a wide-bodied aircraft. The last measure proposed for evaluating connection quality is Frequency Factor (FF). Normally, the more frequently an O\&D pair is served, the more value passengers perceive; this is particularly true if no direct link between the O\&D pair exists, or if the amount of direct seats available on the route is limited (rendering one-stop alternatives more attractive). Frequency Factor rewards/penalises connections according to their weekly frequency, also taking into consideration the availability of direct seats on the respective O\&D market. Finally, having calculated all the quality factors, the HCPA establishes the connection quality matrix, which lists the quality indexes $(\mathrm{QCI})$ for all viable connections (QVC).

Connection quality $(\mathrm{QCl})$, as calculated by the model, is useful for another reason: it can be used to compare the perceived value of a connection with that of an equivalent direct service. In fact, a connection is considered to bear exactly the same value as that of an average direct flight when its $\mathrm{QCl}$ equals $100 \%$. In other words, each connection meeting the following conditions can be regarded as one average direct flight between the same O\&Ds:

- Overall detour is zero

- Transfer time is infinitesimal

- Seat capacity of each leg is average

- One leg is operated by a narrow-body and the other by a wide-body

- Daily frequency is offered and no direct seats are available

When the combination of the aforementioned factors results in a quality index greater than $100 \%$ the connection is more valuable than an average direct flight and viceversa. 


\subsection{Hub Connectivity Performance Metrics and Methodology Discussion}

After the quantity module has identified all viable connections (QVC) and the quality module has attached a quality index to each one (QCI), an indicator of the hub's overall connecting performance can be derived, as shown in Equation 2. The Hub Connectivity Performance Index ( $\mathrm{HCPI})$ is calculated as the sum of the qualities of all viable connections.

$$
\mathrm{HCPI}=\sum_{\text {conx }=1}^{\mathrm{QVC}}\left(\mathrm{QCI}_{\text {conx }} \cdot 100 \%\right)
$$

HCPl's absolute value represents the number of equivalent average direct flights offered through the hub; for example, if HCPI is found to be 45,000 , this implies that all the arriving and departing services through the hub are equivalent to 45,000 average direct flights between the same O\&Ds ('average direct flight' has been defined in Section 3.2).

In addition, when compared to the number of viable connections (QVC), the HCPI indicates how efficient the hub is in consolidating and re-distributing connecting traffic. Hub Efficiency $(\varphi)$ metric is therefore defined using Equation 3 and is expressed as a percentage. In other words, Hub Efficiency $(\varphi)$ is a measure of how efficiently resources (available flights which satisfy MCT and MACT constraints) are utilised to create connecting opportunities of substantial value to the passengers.

$$
\varphi=\frac{\mathrm{HCPI}}{\mathrm{QVC}} \cdot 100 \%
$$

The basis for the development of the HCPA was our earlier work in this field (Li et al., 2012). As highlighted before, most researchers tend to focus on analysing quantity of connections, experimenting with MCT and MACT parameters. In addition, routing and time factors have received increased attention in various studies. However, research in the direction of analysing connection quality and perceived value from a passenger's perspective has been limited. Most studies treat all connections equally, without considering the number of seats involved in each one. For example, a connection involving two Embraer 170s and one between two Airbus 380s would be counted the same, whilst in fact the latter carries significantly higher value than an average connection. Furthermore, despite some researchers have studied the valueadding effect of frequency, this has not been done in conjunction with analysing the supply of direct seats between the same O\&D pair; indeed, no matter how frequently an O\&D market is served through a hub, if supply of direct seats is large, the indirect services will carry limited incremental value. The study also contributes in 
establishing a measure of connection quality with regards to the equipment type and quality of in-flight product. Two connectivity performance metrics are proposed to be used for the positioning of hub carriers in the competition map; also, the concept of 'average direct flight' is defined and used for interpreting the results. All in all, the HCPA methodology contributes a new approach in measuring hub connectivity by incorporating additional factors into the analysis and establishing more robust relationships between the various influences.

\subsection{Results: Hub connectivity analysis and network performance for Turkish Airlines and Emirates}

The analysis only focuses on connecting flights and excludes direct services altogether. The contribution of direct services is important only when a strong source market exists; although Istanbul is indeed a strong outbound market, the same does not hold true for Dubai, despite the recent attempts to establish it as such. As a consequence, focusing the analysis only on connecting flights will facilitate the benchmarking of the results.

\subsection{Analysis of Turkish Airlines' Istanbul hub, 2007-2016}

Analysing schedules for the first week of July in 2007, the HCPA has indicated that the total number of viable connections is 33,069 . However, because of the poor quality of many of those connections, the final effective figure drops to 19,230. Hub efficiency was also calculated and equals $58.2 \%$, which implies that out of all hits only $58.2 \%$ have the same value as an average direct flight between the respective O\&Ds (Figure 1).

Since 2007, Turkish has expanded its fleet and added many destinations to its network. However, although increasing the scale of operations theoretically creates more connecting opportunities, it does not guarantee better hub performance; aligning flights schedules is a critical process in this direction. For the first week of July 2014 , the number of inbound/outbound flights was 3,067/3,065, respectively. These figures are over twice as high as those of 2007, but as the connectivity advantage increases in proportion to the square of the number of direct flights, the boost in hits is expected to be significant. Indeed, the analyser yielded the effective number of hits to be 103,368 out of a total of 150,580 viable connections. In other words, the number of equivalent average direct flights offered is 103,368 , whilst in 
2007 it was just 19,230 . The effective number of hits rose $438 \%$ within seven years, resulting from both the increase in the scale of operations and the improved efficiency of the hub. Better coordination of schedules at the hub affected its efficiency positively, which rose by $17.9 \%$ and equals $68.6 \%$ in 2014 .

As an update, the analysis was also repeated for provisional July 2016 schedules. In particular, during the first week of July 2016, Turkish scheduled 3,523 inbound and 3,523 outbound flights, representing a 15\% increase of services compared to 2014 . This increase is modest compared to the one realised between 2007 and 2014 as airport capacity constraints have prevented further growth. The model predicted that a total of 119,458 hits will be of value, out of 169,888 viable connections. In other words, a $15 \%$ increased level of activity at the airport will lead to nearly $16 \%$ incremental effective connections. This proportional improvement stems from the good average hub efficiency attained at the airport, which for 2016 stands at $70.3 \%$.

Despite the fact that Turkish Airlines has significantly refined its hub's operation during the past nine years from 2007 to 2016 , the overall efficiency of $70.3 \%$ signifies that there is still room for improvement. Moreover, given that IST operates nearly under capacity, Turkish cannot add more flights until the new airport becomes operational; as a result, the carrier needs to focus on adjusting flight schedules in order to increase the effective number of hits.

\subsection{Analysis of Emirates' Dubai hub, 2008-2016}

In 2008, Emirates had scheduled 882 inbound and 880 outbound flights arriving and departing through its hub in Dubai International Airport (DXB). The HCPA calculated that the total number of hits attained was 20,205 , while, after the assessment of hit quality, this figure drops to 16,196 . The implications for hub performance are clear: its efficiency totalled $80.2 \%$, or in other words, out of all hits, $80.2 \%$ had the same quality as an average direct flight. This figure is considerably high and indicates that the temporal coordination of operations at DXB was very effective in 2008 (Figure 2).

In 2014, Emirates had grown its fleet by purchasing larger aircraft. This strategy provided the airline with the capability to increase its market share without increasing its frequencies. Apart from introducing bigger aircraft, by 2014 Emirates had also expanded its network, serving more destinations and offering 1,298 inbound and 1,298 outbound weekly flights to/from its hub, respectively. According to the HCPI, the total number of hits is 38,486 with 29,507 connections bearing the same quality 
as an average direct flight. These figures signal an increase of $90.5 \%$ and $82.2 \%$ in the absolute and effective number of hits, respectively. Because absolute hits grew more than effective ones, the hub's performance is expected to be lower. Indeed, the results show that a performance drop of $4.3 \%$ is realised with hub efficiency totalling $76.7 \%$ in 2014 . This drop in efficiency is small, and the absolute figure of $76.7 \%$ is still high. According to OAG data, Emirates expanded its network in America by adding eight new airports and 70 additional weekly flights from 2008 to 2014 . However, U.S. is ideally served from DXB with direct services rather than indirect ones because of the high detours involved when sourcing traffic from Europe or AsiaPacific. As a result, all such connections in 2014 were penalised due to excessive routing factors, leading to slightly decreased hub efficiency.

What is interesting to note is how Emirates' accelerated expansion between 2014 and 2016 influenced its hub performance. The analysis was performed using 2016 schedule data, and results show that the total quantity of viable connections increased by $87 \%$ while effective hits rose by $192 \%$. This growth comes as a result of Emirates' aggressive fleet expansion/renewal programme; in fact, within two years, Emirates expanded its wide-body fleet by adding 22 777s and 30 A380s. These aircraft were used to boost frequency and/or seat capacity on existing routes and also to launch 15 new destinations. In addition, as Emirates has scheduled most of its flights over three daily waves at DXB, incremental capacity was deployed very effectively, feeding into the overall hub efficiency, which exceeded $100 \%$ (119.4\%).

\subsection{Connectivity Benchmark between Turkish Airlines and Emirates}

Figure 3 summarises the connectivity analysis results comparing the connectivity performance of the two carriers. Turkish Airlines provides more effective hits than Emirates, totalling 103,368 equivalent average direct weekly flights over Emirates' 29,507. The difference of 73,861 hits is large and provides Turkish with an unparalleled advantage when it comes down to overall connecting opportunities. In addition, Turkish's absolute number of attained hits is $291 \%$ higher than that of Emirates; this implies that if Turkish Airlines re-organises its schedules accordingly, it can attain a huge benefit in hits that Emirates will be unable to match.

However, the considerably high number of hits attained by Turkish Airlines can be attributed to its high frequencies and its network structure. As Turkish is primarily targeting the European market and also builds upon Turkey's large domestic traffic, it is committed to providing high frequencies on short sectors. On the contrary, Emirates serves geographically dispersed markets with long-haul, low-frequency 
flights. As a result, the observed gap between effective hits offered by the two carriers is a natural consequence of the fundamental differences between the carriers' network strategies.

What is important for benchmarking purposes though is hub efficiency. As shown in Figure 3, Emirates prevails with an average efficiency of $76.7 \%$, compared to Turkish's $68.6 \%$. As hub efficiency is largely affected by the temporal configuration of banks, this figure reflects that Emirates manages to exploit its resources more effectively than Turkish Airlines and in the long run will realise more benefits.

\subsection{Connectivity Benchmark between Turkish Airlines, Emirates and their Partners}

The next benchmark between the two carriers aims to reveal which partnership strategy achieves better results from a hub connectivity perspective. Figure 4 summarises findings for 2014 for both carriers, including their partners' contribution.

Qantas flights boosted both absolute and effective hits attained at DXB, facilitating Emirates in building a well-utilised hub (84.5\%). Similarly, Turkish realised an increase in absolute and effective hits when its partners' flights were included; however, its overall efficiency only rose marginally (70.7\%). As a first conclusion, it seems that the Emirates/Qantas partnership has performed better than Turkish's alliance code-sharing, primarily because of its high contribution to hub efficiency. Table 3 compares the increase in absolute and effective hits for the two carriers contributed by their partners' services. In both cases, HCPI increased more than QVC, which implies that their partners' connections carried significantly higher quality than average; this is reflected in differential hub efficiency. It is also evident that between the two carriers, Emirates with its partner, Qantas, introduced flights with quality almost three times higher than average, while Turkish's partners delivered an excessive quality by a factor of 1.26 .

Therefore, the quality of Qantas' services is considerably higher than that of an average flight and provides more value than the larger in quantity but lower in quality services of Turkish's partners. It is thus clear that Emirates has built its network strategy upon providing fewer higher-than-average-quality services while Turkish targets more average-quality or lower-than-average-quality services. As a result, partnering with carriers that follow coherent approaches and will bolster their qualityor quantity-oriented strategies was the way forward for Emirates and Turkish when they decided to grow inorganically. 
At this point, it is important to clarify that 'average quality' does not refer to the real quality of the airline product: it only serves as a benchmark representing the attributes of an average indirect flight, as defined in section 3.2.

\subsection{Connectivity Benchmark: Market Breakdown}

The analysis so far has focused on hub overall performance. However, most airline hubs target only select flows rather than attempting to cater for all (Goedeking, 2010). Each airline's strategic focus is different and depends on various factors, such as business and trade flows, population/economic growth and existing Air Service Agreements (ASAs). However, the factor that largely affects how effectively an airline can serve certain markets is its hub's location. Consequently, the analysis of connecting opportunities offered on a per-market basis will reveal the top three flows on which Turkish Airlines and Emirates go head-to-head. Results are presented in Figure 5.

The most important transfer market for both Turkish Airlines and Emirates is the one between Europe and Asia-Pacific. Istanbul and Dubai are located in a strategic position, which minimises detours for indirect services between these two regions. Turkish is offering 8,662 effective hits per week, the highest among its network, and accomplishes a relatively high hub efficiency of $74 \%$. However, results show that Emirates' performance in this market cannot be matched by its competitor. Offering 10,067 weekly connections with the same quality as a direct service, it is identified as the superior performer within this market, securing a very strong competitive edge. Moreover, it accomplishes an excellent efficiency of $161 \%$, attributed to the very high quality of its services. Table 4 lists some interesting statistics about the quality attributes of hits provided by Turkish Airlines and Emirates in this market. According to the table, the superior quality of Emirates' services results from the advantageous routing and service quality factors, convenient number of frequencies offered and better transfer timings.

The second most important transfer market where both Turkish and Emirates fiercely compete is the one between Europe and Africa. Despite the larger detours involved (given an average detour threshold of $33 \%, 75 \%$ of Turkish's connections and only $44 \%$ of Emirates' total hits fall within this range), this market proves to be highly competitive. Turkish offers 5,113 weekly hits, maintaining an average efficiency of $54 \%$ and securing its dominant position over Emirates, which provides significantly fewer connections $(1,049)$. Turkish's superiority arises from less notable detours, more convenient frequencies, fewer direct competitor seats, and better transfer 
timings, compared to Emirates' propositions. Although Emirates still achieves a superior efficiency $(71 \%)$, this is irrelevant from a passenger's perspective: the more effective hits the hub provides, the more likely it is that passengers will opt for a transfer at that hub (excluding the effect of fares). Consequently, Turkish Airlines, with $387 \%$ more hits than Emirates, prevails. However, as the African market develops, there will be plenty of opportunities for Emirates to catch up in the coming years, provided it remains focused on this market.

Finally, the transfer market between the Middle East and America is the last one targeted by both carriers. The direction of traffic provides Istanbul with a natural geographical advantage, leading to marginal detours and very high efficiencies. Indeed, Turkish offers 382 weekly hits with an efficiency of $81 \%$, the highest among its primary markets. Despite the fact that Emirates' network is more developed in the U.S., it fails to produce as many hits as its competitor, totalling 174 per week, although it achieves a marginally higher efficiency (83\%). The scale of Turkish's operations in the Middle East overcompensates for its weaker presence in America, rendering the Turkish carrier as the dominant one, in terms of hits attained. 


\subsection{Discussion and Conclusions}

The hub performance of two influential airlines, Turkish Airlines and Emirates, was analysed using the new methodology proposed in this study under the name 'Hub Connectivity Performance Analyser (HCPA)'. This approach consolidates the results into two metrics: the Hub Connectivity Performance Index (HCPI), which is the number of hits that bear quality equivalent to that of an average direct flight, and the Hub Efficiency $(\varphi)$, an indirect measure of the average quality of connections, which also indicates how effective the temporal configuration of a hub is. The outcomes of this case study, as presented below, illustrate the intrinsic strategic focus that Emirates and Turkish Airlines have each adopted regarding their hub/network configuration, while also highlight the importance of hub efficiency for the success and sustainability of the hub-and-spoke network model.

\section{Emirates accomplishes superior hub efficiency; however, dominance is split on a market breakdown basis.}

Results show that Emirates, being highly focused on a 'connect the world through Dubai' strategy, has managed to build a highly efficient hub where almost $85 \%$ of all attained connections bear the same value to that of direct service between the same O\&Ds. On the contrary, Turkish ranks second as its hub performance was found to be inferior to that of Emirates with an efficiency of only $70.7 \%$. The aforementioned efficiency also incorporates the effect of the carriers' primary alliance/code-share partners, which was deemed to be positive in both cases.

Despite the common belief that positions the two carriers as strong rivals, it was shown that they only compete in three out of the five top transfer markets each can serve best. The split of dominance between their common markets is even. In fact, Emirates benefits from its bold presence in the Asia-Pacific region, being the dominant carrier in the transfer market to Europe. Turkish Airlines' privileged hub location for transfers between the Middle East and America leads to superior hub performance in this market. Finally, Turkish provides more transfer opportunities between Europe and Africa, but Emirates attains considerably higher hub efficiency, which places the carrier in a better position for future expansion in that market.

\section{Turkish Airlines network strategy: not optimised for connecting traffic.}

Contrary to the UAE and Dubai, Turkey has a huge domestic market, and Istanbul is a big outbound market. As a result, Turkish has followed a 'hybrid' network strategy, split between the ambition to serve these markets and also to increase the share of its transfer passengers. Thus, adopting a point-to-point approach on European and 
domestic destinations, dictated by the high direct competition from LCCs and other flag carriers, has undoubtedly corroded its 'intercontinental connector' strategy. Being in a position to serve a large number of short-haul destinations, Turkish has adopted a de-peaked rolling hub configuration to enhance its competitiveness in such markets. However, this configuration contradicts the connectivity maximisation objective. Although Turkish's very large scale of operations partially compensates for this inherent inefficiency, when it all comes down to competition with a superconnector ${ }^{1}$ like Emirates, Turkish ranks second. The only exceptions to this conclusion are transfer markets where the geographical position of super-connectors' hubs result in poor connection quality, attributed to high geographical detours.

\section{Hub efficiency is of paramount importance for Emirates' success, and the short-term solution to air traffic bottlenecks.}

On the other hand, Emirates' strategy of only focusing on trunk routes that can fill its wide-bodies has resulted in fewer connecting opportunities for passengers transferring in Dubai. As a result, maintaining a high overall efficiency at its hub is key in ensuring that its ongoing expansion will strengthen its competitive position in the intercontinental transfer market. Last but not least, as passenger traffic is rapidly approaching capacity limits in both IST and DXB, the two carriers might be unable to expand their services through the addition of more aircraft or higher frequencies. Emirates has opted for expansion through aircraft gauge thus bypassing any capacity-related constraints in the short-run. However, the only way forward for Turkish is to target higher hub efficiency before starting to disrupt its operations by positioning aircraft to secondary hubs in Istanbul or Ankara.

The preceding analysis evaluated airline network connectivity/hub performance considering both quantity and quality aspects, which, together, constitute key elements of the value airline services provide to passengers. However, the methodology proposed also carries some limitations. First of all, bi-directionality of connections was not taken into account; bi-directionality is important as it guarantees that for every viable connection a similar return connection exists within the period of one week. Moreover, MACT values are subjective and depend on passenger tolerance of maximum waiting time on the ground. Calculation of variable MACT limits with the aid of a probabilistic model might add to the significance of the findings. Another concern that can be raised is whether hub connectivity should be used as a benchmarking metric at all. The underlying number of seats on any

\footnotetext{
${ }^{1}$ Super-connector: any carrier that primarily targets connecting traffic and has optimised its hub's temporal configuration in order to facilitate connectivity.
} 
connection varies, depending on size of aircraft involved; thus, the question of whether seat supply would be a more appropriate measure of connectivity performance for benchmarking purposes remains to be answered. Last but not least, the exclusive reliance on OAG schedule data restricts the analysis to capacity-side. However, the real commercial value of connections can only be established if airline passenger demand data (such as paxIS or MIDT) are used in conjunction with flight schedules. This will reveal which connections attract higher passenger demand and thus are more valuable. Similarly, a yield factor can also be introduced to emphasize connections with high earning potential for the airline. Further study on this subject could elaborate on the limitations mentioned above and should also consider incorporating route revenue and cost figures to examine network performance from a commercial viewpoint. 


\section{References}

Bania, N., Bauer, P. W. and Zlatoper, T. J. (1998), "U.S. Air Passenger Service: a Taxonomy of Route Networks, Hub Locations and Competition", Transportation Research Part E: Logistics and Transportation Review, vol. 34, no. 1, pp. 53-74.

Bootsma, P. D. (1997), Airline Flight Schedule Development: Analysis and Design Tools for European Hinterland Hubs, Elinkwijk B.V., Utrecht.

Budde, A., de Wit, J. and Burghouwt, G. (2008), "Borrowing from Behavioural Science: A Novel Method for the Analysis of Indirect Temporal Connectivity at Hub Airports", Proceedings of the Air Transport Research Society Conference, 6-10 July 2008, Athens, .

Burghouwt, G. and de Wit, J. (2005), "Temporal Configurations of European Airline Networks", Journal of Air Transport Management, vol. 11, no. 3, pp. 185-198.

Burghouwt, G. and Redondi, R. (2013), "Connectivity in Air Transport Networks: An Assessment of Models and Applications", Journal of Transport Economics and Policy (JTEP), vol. 47, no. 1, pp. 35.

Burghouwt, G. (2007), Airline Network Development in Europe and its Implications for Airport Planning, Ashgate, Aldershot, England; Burlington, VT.

Coldren, G. M. and Koppelman, F. S. (2005), "Modeling the Competition Among AirTravel Itinerary Shares: GEV Model Development", Transportation Research Part A, vol. 39, pp. 345-365.

Danesi, A. (2006), "Measuring Airline Hub Timetable Co-Ordination and Connectivity: Definition of a New Index and Application to a Sample of European Hubs", European Transport, vol. 34, pp. 54-74.

Dennis, N. (1998), "Competition Between Hub Airports in Europe and a Methodology for Forecasting Connecting Traffic", Proceedings of the 8th World Conference on Transport Research, 12-16 July 1998, Antwerp, pp. 12.

Dennis, N. (1994a), "Airline hub operations in Europe", Journal of Transport Geography, vol. 2, no. 4, pp. 219-233.

Dennis, N. (1994b), "Scheduling Strategies for Airline Hub Operations", Journal of Air Transport Management, vol. 1, no. 3, pp. 131-144.

Doganis, R. and Dennis, N., (1989), Lessons in Hubbing, $42-7$ ed., Airline Business.

Goedeking, P. (2010), Networks in Aviation: Strategies and Structures, XVII ed, Springer, Heidelberg.

Grosche, T. (2009), Computational Intelligence in Integrated Airline Scheduling, Springer-Verlag, Berlin. 
Li, W., Miyoshi, C. and Pagliari, R. (2012), "Dual-Hub Network Connectivity: An Analysis of All Nippon Airways' Use of Tokyo's Haneda and Narita Airports", Journal of Air Transport Management, vol. 23, pp. 12-16.

Lijesen, M. G. (2004), Home Carrier Advantages in the Airline Industry (PhD thesis), VU University, Amsterdam.

Malighetti, P., Paleari, S. and Redondi, R. (2008), "Connectivity of the European Airport Network: 'Self-help Hubbing' and Business Implications", Journal of Air Transport Management, vol. 14, no. 2, pp. 53-65.

Matsumoto, H., Veldhuis, J., de Wit, J. and Burghouwt, G. (2008), "Network Performance, Hub Connectivity Potential and Competitive Position of Primary Airports in Asia/Pacific Region", Proceedings of the Air Transport Research Society Conference, 6-10 July 2008, Athens.

Seredyński, A., Rothlauf, F. and Grosche, T. (2014), "An Airline Connection Builder Using Maximum Connection Lag with Greedy Parameter Selection", Journal of Air Transport Management, vol. 36, no. 0, pp. 120-128.

Shaw, S. (1993), "Hub Structures of Major US Passenger Airlines", Journal of Transport Geography, vol. 1, no. 1, pp. 47-58.

Shaw, S. and Ivy, R. L. (1994), "Airline Mergers and their Effect on Network Structure", Journal of Transport Geography, vol. 2, no. 4, pp. 234-246.

Suau-Sanchez, P. and Burghouwt, G. (2012), "Connectivity Levels and the Competitive Position of Spanish Airports and Iberia's Network Rationalization Strategy, 2001-2007", Journal of Air Transport Management, vol. 18, no. 1, pp. 47-53.

van Dalen, P. (2011), Threat of De-Hubbing for Amsterdam Airport Schiphol: Rationale Behind Air France-KLM's Dual-Hub Strategy (M.Sc. thesis), Cranfield University, Cranfield, UK.

Veldhuis, J. (1997), "The Competitive Position of Airline Networks", Journal of Air Transport Management, vol. 3, no. 4, pp. 181-188.

Veldhuis, J. and Kroes, E. (2002), "Dynamics in Relative Network Performance of the Main European Hub Airports", Proceedings of the European Transport Conference, 9-11 September 2002, Cambridge. 
Figure 1: Turkish Airlines' Istanbul hub performance in 2007, 2014 and 2016.

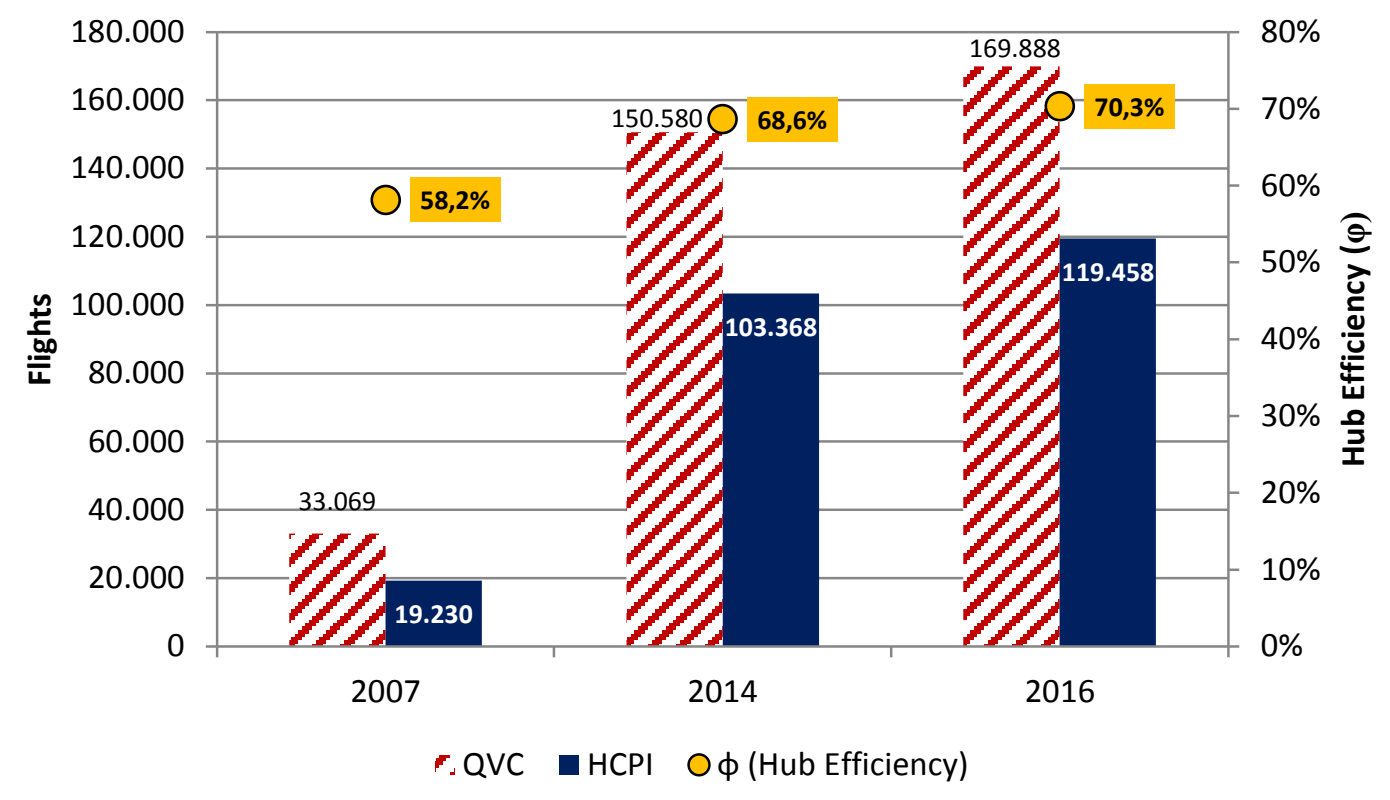


Figure 2: Emirates' Dubai hub performance in 2008, 2014 and 2016.

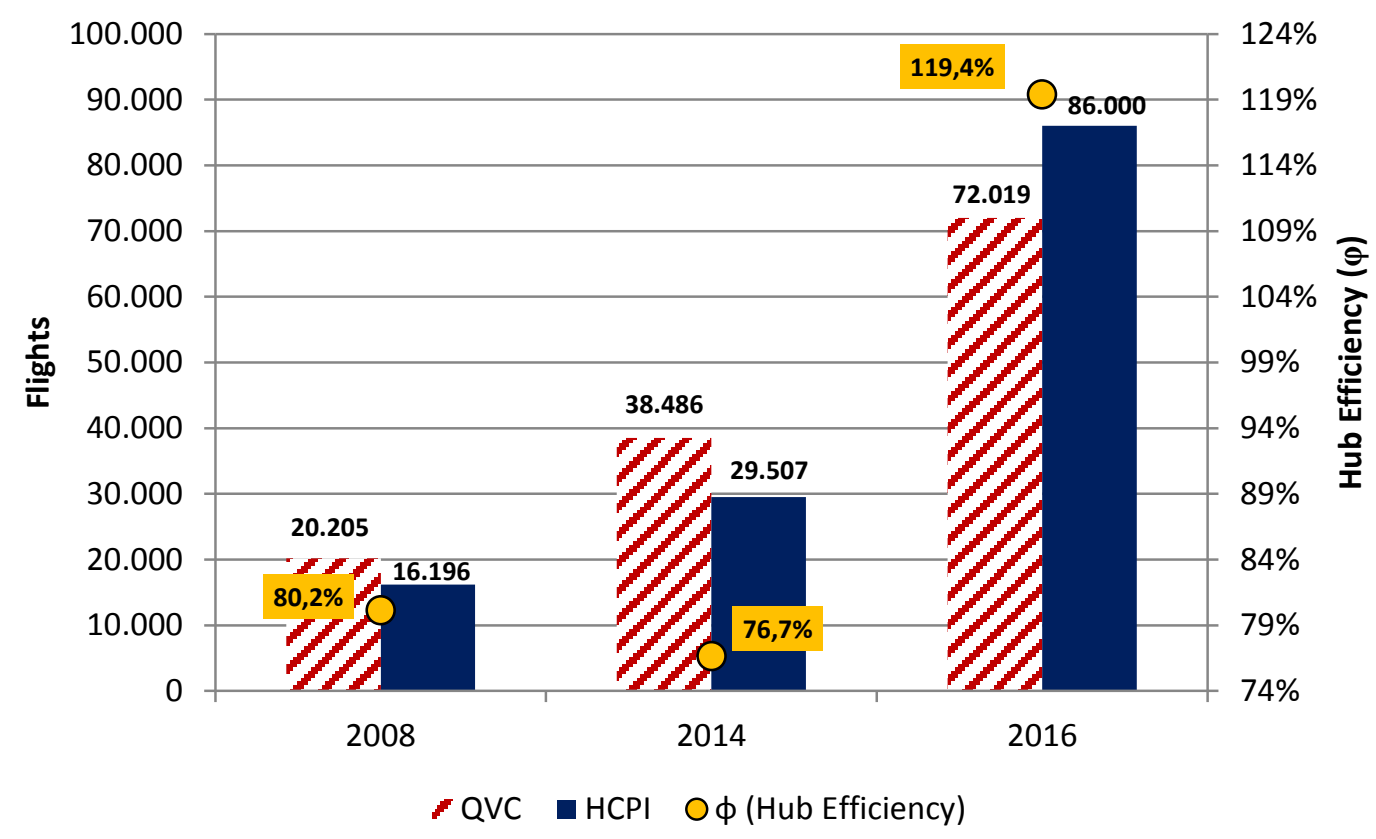


Figure 3: Hub connectivity benchmark: Turkish Airlines' Istanbul hub vs Emirates' Dubai hub, 2014.

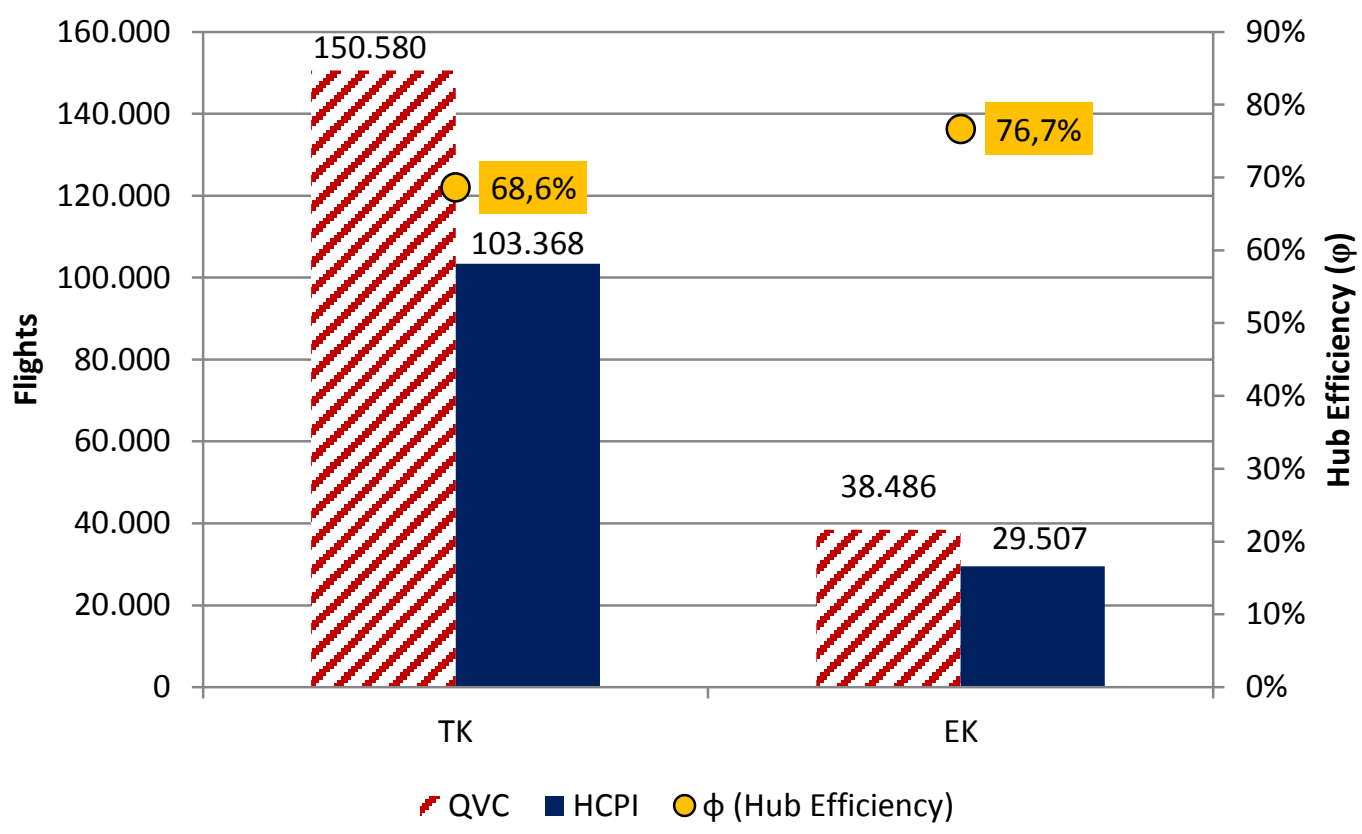


Figure 5: Network performance of Turkish Airlines and Emirates in their top-3 O\&D flows.

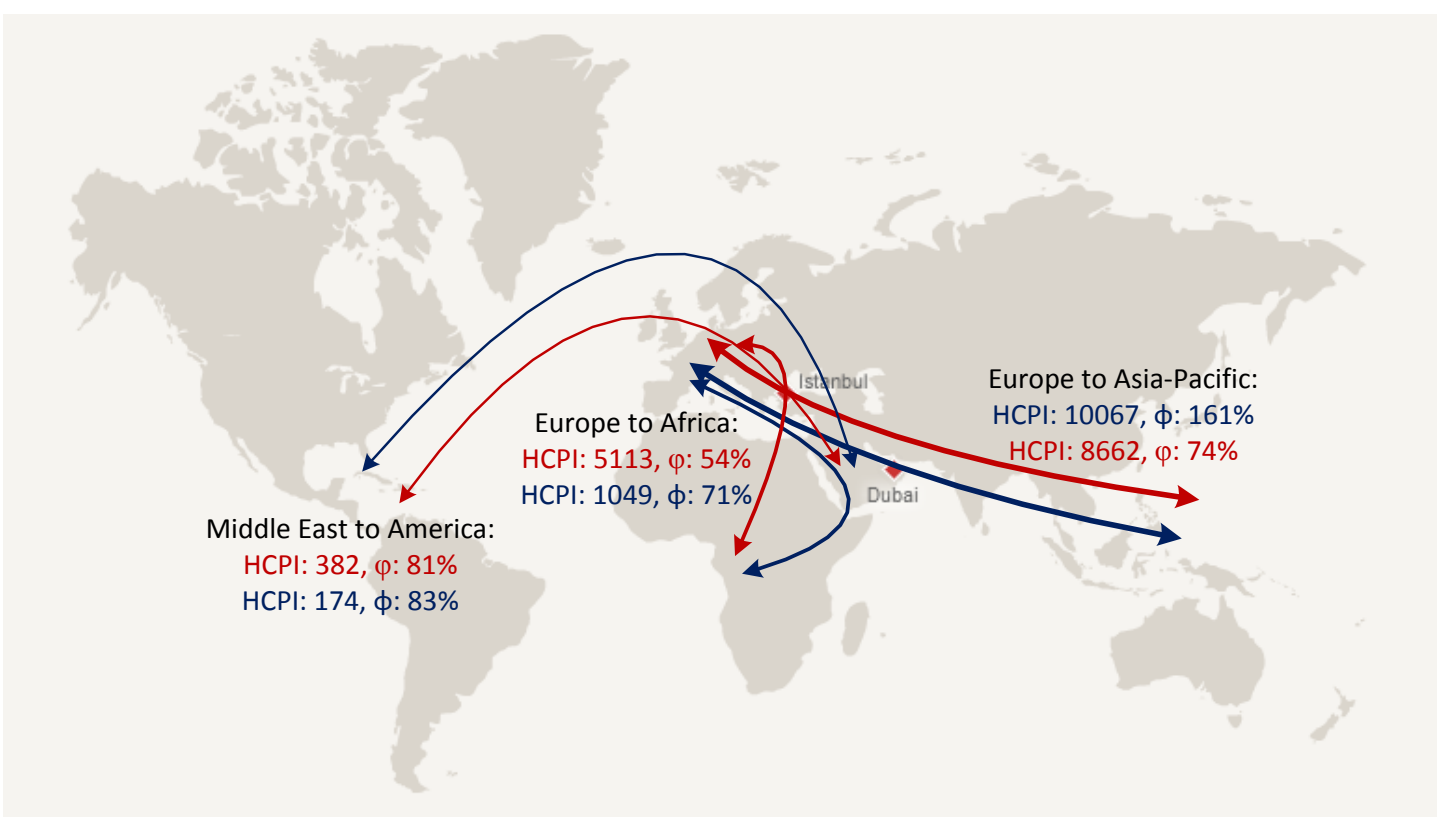

Note: Blue lines and figures refer to Emirates. Red lines and figures refer to Turkish Airlines. Line width denotes market importance. 
Table 1: MACT values and routing factors (R.F.) proposed in past literature.

\begin{tabular}{|c|c|c|}
\hline Authors & MACT & Notes \\
\hline Doganis and Dennis (1989) & $90^{\prime}$ & Fixed to 90 minutes for all types of connections \\
\hline Burghouwt and de Wit (2005) & $180^{\prime} / 300^{\prime} / 720^{\prime}$ & $\begin{array}{l}\text { Values correspond to connection types: Intra- } \\
\text { continental/mixed/intercontinental }\end{array}$ \\
\hline Danesi (2006) & $120^{\prime} / 180^{\prime} / 180^{\prime}$ & Note as above \\
\hline Park et. al (2010) & $180^{\prime} / 840^{\prime}$ & If total elapsed time $<8 \mathrm{hrs} /$ otherwise \\
\hline Veldhuis (1997) [Netscan model] & $\mathrm{n} / \mathrm{a}$ & $\begin{array}{l}\text { Veldhuis used 'Perceived Total Travel Time' } \\
\text { instead. Connection time is penalized by a } \\
\text { factor of } 3 \text { and added to total flight time. }\end{array}$ \\
\hline Authors & R.F. & Notes \\
\hline Burghouwt and de Wit (2005) & 1.4 & 1.25 standard +0.15 for airport slacks \\
\hline Danesi (2006) & 1.5 & Maximum acceptable value \\
\hline Park et. al (2010) & 1.5 & Maximum acceptable value \\
\hline Suau-Sanchez and Burghouwt (2012) & 1.7 & Maximum acceptable value \\
\hline Goedeking (2010) & $1.2 / 1.35-2.50$ & $\begin{array}{l}\text { Values correspond to connection types: } \\
\text { Maximum acceptable for long-haul/ acceptable } \\
\text { range for short-haul }\end{array}$ \\
\hline Malighetti et. al (2008) & $\mathrm{n} / \mathrm{a}$ & $\begin{array}{l}\text { Unconstrained routing factor. Researchers } \\
\text { observed that hardly any fastest connections } \\
\text { exceed } 1.4\end{array}$ \\
\hline
\end{tabular}


Table 2: Minimum and maximum connecting times for Turkish Airlines' operations at Istanbul (IST) and Emirates' operations at Dubai (DXB).

\begin{tabular}{lcc}
\hline Type of connection & Minimum (MCT) & Maximum (MACT) \\
\hline & Istanbul Ataturk (Turkish Airlines) \\
\hline Domestic - Domestic & 30 minutes & 90 minutes \\
Domestic - International & 90 minutes & 270 minutes \\
International - Domestic & 75 minutes & 225 minutes \\
International - International & 60 minutes & 180 minutes \\
\hline & \multicolumn{2}{c}{ Dubai International (Emirates) } \\
\hline International - International & 75 minutes & 225 minutes \\
\hline
\end{tabular}


Table 3: Comparison of partners' contribution between Turkish Airlines and Emirates.

\begin{tabular}{l|c|c|c}
\hline \multirow{2}{*}{ Carriers } & \multicolumn{2}{|c|}{ Difference } & \multirow{2}{*}{$\begin{array}{c}\text { Differential Hub } \\
\text { Performance }\end{array}$} \\
\cline { 2 - 3 } & QVC & HCPI & $126 \%$ \\
\hline TK + STAR & 5,606 & 7,083 & $293 \%$ \\
\hline
\end{tabular}


Table 4: Connection quality break-down for Turkish Airlines and Emirates in the Europe to Asia-Pacific transfer market (2014).

\begin{tabular}{l|cc|cc}
\hline \multirow{2}{*}{ Connection quality attributes } & \multicolumn{2}{|c|}{ Connections } & \multicolumn{2}{c}{$\%$ of } \\
\cline { 2 - 5 } & QVC \\
\hline Detour less than 11\% & EK & TK & EK \\
No direct seats available & 6,361 & 4,293 & $54 \%$ & $69 \%$ \\
Transfer occurs between 17:00-06:59 & 10,105 & 5,123 & $86 \%$ & $82 \%$ \\
Daily frequency or higher & 5,820 & 4,191 & $75 \%$ & $67 \%$ \\
Both legs flown on wide-bodies & 612 & 4,371 & $49 \%$ & $70 \%$ \\
\hline
\end{tabular}


2016-10-15

Network performance and competitive impact of the single hub - A case study on Turkish Airlines and Emirates

\author{
Logothetis, Michail
}

Elsevier

Logothetis M, Miyoshi C, Network performance and competitive impact of the single hub - A case study on Turkish Airlines and Emirates, Journal of Air Transport Management, Vol. 69, June 2018, pp. 215-223

http://dx.doi.org/10.1016/j.jairtraman.2016.10.003

Downloaded from Cranfield Library Services E-Repository 